\title{
Pengaruh Pembebanan Overload Bucket Terhadap Kekuatan Material Komponen Arm Pada Excavator Hitachi 2500 Tipe Backhoe
}

\author{
Lia Pongsapan \\ Program Studi Teknik Mesin Fakultas Teknologi Industri Universitas Balikpapan \\ Jalan Pupuk Raya PO BOX 335 Balikpapan \\ Email: lia_ftiuniba@yahoo.com
}

\begin{abstract}
Process coal mining use hitachi excavator 2500 type of backhoe to lift of coal and top soil. Maximum capacities of bucket according to manufacturer standard is 27 ton, but actually bucket of overload condition with payload capacities go up 37,95 ton. This research analyse strength component of arm at condition of overload activity. Material of Arm is material of structural SS400 steel with permission tension boundary (yielding point) equal to 205-245 N/mm ${ }^{2}$ and at second part of bracket tied on material HT 590 with permission tension boundary (yielding point) 500-515 $\mathrm{N} / \mathrm{mm}^{2}$. The result showed that the components arm at condition overload activity has force and tension increase 23-27 \% from condition of normal activity. Maximum tension at front hydraulic cylinder pivot $62,704 \mathrm{~N} / \mathrm{mm}^{2}$, while maximum tension at bracket happened in bracket slider bushing at condition overload activity $428 \mathrm{~N} / \mathrm{mm}^{2}$. Value both of the tension smaller than material permission tension so that materials at component of arm in compliance with applicable standards and met the eligibility safe condition.
\end{abstract}

Keywords : Bucket excavator, condition of overload activity, analyse strength, safe condition.

\begin{abstract}
Abstrak
Proses penambangan batubara menggunakan excavator hitachi 2500 tipe backhoe untuk mengangkat batubara dan top soil. Kapasitas maksimum bucket sesuai standar pabrikan adalah 27 ton, tetapi kenyataan di lapangan bucket mengalami overload dengan kapasitas muatan naik sampai 37,95 ton. Penelitian ini menganalisa kekuatan komponen arm menahan bucket pada kondisi kerja overload. Material arm terbuat dari material structural steel SS400 dengan batas tegangan ijin (yielding point) seesar 205-245 N/mm dan pada bagian bracket disambung dengan material HT 590 dengan batas tegangan ijin (yielding point) sebesar 500-515 N/mm ${ }^{2}$. Hasil penelitian memperlihatkan kenaikan nilai gaya dan tegangan pada komponen arm pada kondisi pembebanan overload sebesar 23-27 \% dari kondisi pembebanan normal. Tegangan maksimum pada front hydraulic cylinder pivot sebesar $62,704 \mathrm{~N} / \mathrm{mm}^{2}$, sedangkan tegangan maksimum pada bracket terjadi di bushing slider bracket pada saat pembebanan overload sebesar $428 \mathrm{~N} / \mathrm{mm}^{2}$. Nilai kedua tegangan tersebut lebih kecil dari tegangan ijin material sehingga material pada komponen arm telah sesuai dengan standar kelayakan dan dinyatakan aman.
\end{abstract}

Kata kunci : Bucket excavator, kondisi kerja overload, analisa tegangan,kondisi aman. 


\section{Pendahuluan}

Proses penambangan batubara di wilayah Kalimantan Timur menggunakan metode penambangan tambang terbuka tepatnya metode open pit mining, secara umum metode ini dapat dikelompokkan menjadi kegiatan pengupasan tanah penutup atau overburden dan kegiatan penambangan batubara yang menggunakan alat berat seperti hydraulic excavator Hitachi EX2500.

Produktivitas didefinisikan sebagai suatu kemampuan seberapa banyak material yang dapat digali oleh excavator tersebut dalam satuan waktu tertentu. Produktivitas excavator dipengaruhi oleh berbagai hal, baik yang berasal dari dalam excavator seperti cara atau kondisi kerja dan kondisi unit excavator itu sendiri, maupun dari luar yang biasanya berasal dari kondisi lapangan tempat excavator tersebut bekerja, dikarenakan salah satu faktor yang mempengaruhi produktivitas adalah kondisi unit excavator.

Penelitian ini menganalisa gaya dan tegangan yang bekerja pada komponen arm unit hydraulic excavator Hitachi EX2500 pada kondisi kerja overload bucket dan menentukan apakah komponen arm mampu dan aman menerima tegangan tersebut.

Kapasitas maksimum bucket sesuai standar pabrikan adalah 27 ton, dimana angka tersebut didapat dari hasil perkalian volume bucket yaitu $15 \mathrm{~m}^{3}$ dengan berat jenis material (material density) yaitu 1.800 $\mathrm{kg} / \mathrm{m}^{3}$. Tetapi pada kondisi aktual, bucket mengalami overload dengan naiknya volume bucket menjadi $16,5 \mathrm{~m}^{3}$ dan berat jenis material yang diangkat yaitu 2.300 $\mathrm{kg} / \mathrm{m}^{3}$, sehingga kapasitas muatan naik mencapai 37,95 ton. Oleh sebab itu, perlu dilakukan perhitungan kekuatan arm untuk menahan bucket pada kondisi kerja overload.

\section{Metode Penelitian}

Metodologi penelitian yang digunakan adalah observasi lapangan. Objek penelitian difokuskan pada komponen arm unit excavator Hitachi EX2500 tipe backhoe yang banyak digunakan pada tambangtambang besar di Indonesia, khususnya di daerah Kalimantan Timur. Prosedur atau langkah-langkah dalam melakukan proses penelitian dan perhitungan adalah sebagai berikut :

a. Melakukan perhitungan beban muatan dan gaya pada saat kondisi pembebanan normal.

b. Melakukan perhitungan beban muatan dan gaya pada saat kondisi pembebanan overload.

c. Menghitung tegangan tarik yang terjadi pada komponen-komponen arm saat pembebanan normal.

d. Menghitung tegangan tarik yang terjadi pada komponen-komponen arm saat pembebanan overload.

e. Membuat diagram perbandingan gaya dan tegangan tarik pada komponenkomponen arm saat kondisi pembebanan normal dan overload.

f. Menyimpulkan apakah material arm mampu dan aman digunakan pada saat kondisi overload.

g. Menghitung persentase kenaikan nilai gaya dan tegangan pada kondisi pembebanan overload.

Gambar 1. berikut ini memperlihatkan pembebanan pada arm excavator hitachi EX2500.

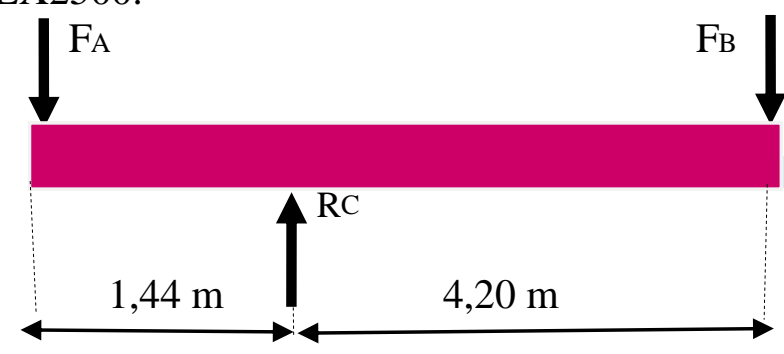

Gambar 1. Free Body Diagram Komponen Arm Excavator Hitachi 2500 Tipe Backhoe. 
Keterangan gambar :

$\mathrm{F}_{\mathrm{A}}=$ gaya yang terjadi pada hydraulic cylinder bracket arm.

$\mathrm{FB}_{\mathrm{B}}=$ gaya yang terjadi pada front hydraulic cylinder pivot (berat total muatan pada bucket).

$\mathrm{Rc}_{\mathrm{C}}=$ reaksi gaya pada tumpuan, yaitu di bushing slider bracket.

Untuk menghitung berat arm digunakanlah rumus sebagai berikut:

$$
w_{\text {arm }}=16.300 \mathrm{~kg} \times 9,807 \mathrm{~m} / \mathrm{s}^{2}=159.854,1 \mathrm{~N}
$$

Berat arm ini memberikan pembebanan yang merata pada seluruh bagian arm, jadi untuk mencari beban merata pada arm digunakan rumus berikut : $q=\frac{159.854,1 \mathrm{~N}}{(1,44+4,20) \mathrm{m}}=\frac{159.854,1 \mathrm{~N}}{5,64 \mathrm{~m}}=28.342,925 \mathrm{~N} / \mathrm{m}$

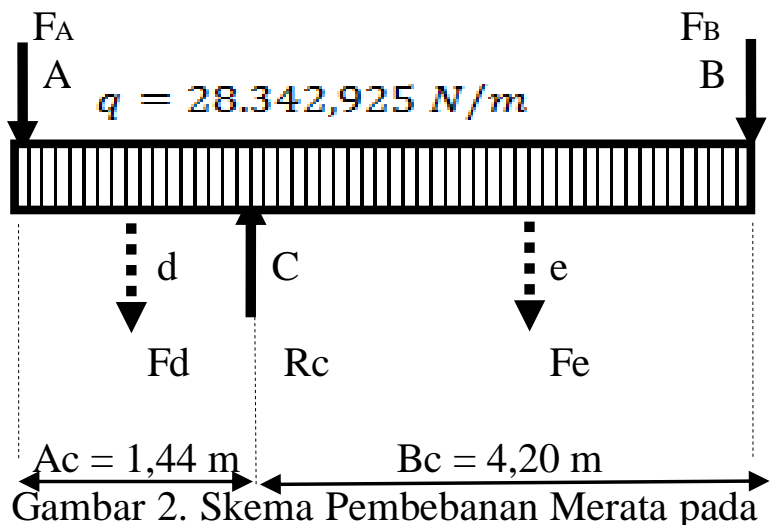

Komponen Arm

\section{Hasil dan Pembahasan}

Menentukan berat total muatan bucket pada kondisi pembebanan standar dilakukan perhitungan massa muatan sebagai berikut :

$$
\begin{aligned}
& \text { a) } m_{\text {muatan }}=\rho \times V_{\text {bucket }} \\
& m_{\text {muatan }}=1800 \mathrm{~kg} / \mathrm{m}^{3} \times 15 \mathrm{~m}^{3}=27.000 \mathrm{~kg} \\
& \text { b) } m_{\text {total }}=27.000 \mathrm{~kg}+12.400 \mathrm{~kg}=39.400 \mathrm{~kg} \\
& \left(R_{C} \times 4,20\right)=7.671 .010,854 \\
& R_{C}=\frac{7.671 .010,854 \mathrm{~N} / \mathrm{m}}{4,20 \mathrm{~m}}=1.826 .431,156 \mathrm{~N}
\end{aligned}
$$

c) $_{F_{B}}=m \times g$

$$
\begin{aligned}
& F_{B}=39.400 \mathrm{~kg} \times 9,807 \mathrm{~m} / \mathrm{s}^{2} \\
& F_{B}=386.395,8 \mathrm{~kg} \cdot \mathrm{m} / \mathrm{s}^{2}, \\
& F_{B}=386,4 \mathrm{kN}
\end{aligned}
$$

Untuk mencari nilai $\mathrm{F}_{\mathrm{A}}$ digunakan konsep keseimbangan momen pada titik c (Mc) sebagai berikut :

$\Sigma M_{c}=0$

$M_{A}+M_{D}-M_{E}-M_{B}=0$

$\left(F_{A} \times d_{a c}\right)+\left(F_{D} \times d_{d c}\right)-\left(F_{E} \times d_{\theta c}\right)-\left(F_{B} \times d_{b c}\right)=$

$\left(F_{A} \times 1,44\right)+\left(F_{D} \times 0,72\right)-\left(F_{E} \times 2,10\right)-\left(F_{B} \times 4,20\right)=$

$\left(F_{A} \times 1,44\right)+(28.342,925 \times 1,44 \times(0,72))$

$(28.342,925 \times 4,20 \times(2,10))-(386.395,8 \times 4,20)=$

$\left(F_{A} \times 1,44\right)+(29.385,945)-(249.984,598)-(1.622 .862,36)$

$\left(F_{A} \times 1,44\right)=1.843 .461,013$

$F_{A}=\frac{1.843 .461,013 \mathrm{~N} / \mathrm{m}}{1,44 \mathrm{~m}}=1.280 .181,3 \mathrm{~N}$

$F_{A}=1.280,18 \mathrm{kN}$

Untuk mencari nilai Rc digunakan konsep keseimbangan momen pada titik $\mathrm{b}\left(M_{b}\right)$

adalah :

$\Sigma M_{b}=0$

$M_{A}+M_{D}-M_{C}+M_{E}=0$

$\left(F_{A} \times d_{a b}\right)+\left(F_{D} \times d_{d b}\right)-\left(R_{C} \times d_{c b}\right)+\left(F_{E} \times d_{a b}\right)=0$

$\left(F_{A} \times 5,64\right)+\left(F_{D} \times 4,92\right)-\left(R_{C} \times 4,20\right)+\left(F_{E} \times 2,1\right)=$ $(1.280 .181,259 \times 5,64)+(40.813,812 \times 4,92)-\left(R_{C} \times 4,20\right.$ $(119.040,285 \times 2,1)=0$

$(7.220 .222,301)+(200.803,955)-\left(R_{C} \times 4,20\right)+(249.984,598)$

Untuk mencari nilai $F_{A}$ digunakan konsep 


$$
R_{C}=1.826,43 \mathrm{kN}
$$

Untuk menghitung berat total muatan pada bucket saat kondisi pembebanan overload, terlebih dahulu cari nilai massa muatan dan massa total pada bucket. Massa muatan pada bucket adalah hasil perkalian massa jenis material (density) dengan volume bucket overload. Volume bucket overload didapat dari hasil perkalian volume bucket standar dengan maksimum bucket fill factor $110 \%$ : $V_{\text {bucket }}=15 \mathrm{~m}^{3} \times 110 \%, \quad V_{\text {bucket }}=16,5 \mathrm{~m}^{3}$

Jenis material muatan pada proses pengupasan (overburden) sangat beragam, material berada pada keadaan alami (bank) atau insitu. Sehingga diambil nilai rata-rata bobot isi material (density) seperti pasir (sand), tanah liat (clay), kerikil (gravel) dan batu kapur (limestone) yaitu $2300 \mathrm{~kg} / \mathrm{m}^{3}$. Massa muatan dan massa bucket bucket pada kondisi pembebanan overload adalah :

$$
\begin{aligned}
& \text { a) } m_{\text {muatan }}=\rho \times V_{\text {bucket }}, \\
& m_{\text {muatan }}=2300 \mathrm{~kg} / \mathrm{m}^{3} \times 16,5 \mathrm{~m}^{3}=37.950 \mathrm{~kg} \\
& \text { b) } m_{\text {total }}=37.950 \mathrm{~kg}+12.400 \mathrm{~kg}=50.350 \mathrm{~kg} \\
& \text { c) } F_{B}=m \times g, \\
& F_{B}=50.350 \mathrm{~kg} \times 9,807 \mathrm{~m} / \mathrm{s}^{2} \\
& F_{B}=493.782,45 \mathrm{~kg} . \mathrm{m} / \mathrm{s}^{2}, \\
& F_{B}=493,78 \mathrm{kN}
\end{aligned}
$$

Hasil perhitungan pada kondisi pembebanan standar dan pembebanan overload dapat dilihat pada tabel berikut :

Tabel 1. Hasil Perhitungan Gaya pada Kondisi Normal dan Overload

\begin{tabular}{|l|l|l|}
\hline $\begin{array}{l}\text { Arah } \\
\text { Gaya }\end{array}$ & $\begin{array}{l}\text { Kondisi } \\
\text { Pembebanan } \\
\text { Standar }\end{array}$ & $\begin{array}{l}\text { Kondisi } \\
\text { Pembebanan } \\
\text { Overload }\end{array}$ \\
\hline FA & $1.280,18 \mathrm{kN}$ & $1.593,39 \mathrm{kN}$ \\
\hline
\end{tabular}

keseimbangan momen titik c (Mc) berikut :

$\Sigma M_{c}=0$

$M_{A}+M_{D}-M_{E}-M_{B}=0$

$\left(F_{A} \times d_{a c}\right)+\left(F_{D} \times d_{d c}\right)-\left(F_{E} \times d_{\theta c}\right)-\left(F_{B} \times d_{b c}\right)=$

$\left(F_{A} \times 1,44\right)+\left(F_{D} \times 0,72\right)-\left(F_{E} \times 2,10\right)-\left(F_{B} \times 4,20\right)=$

$\left(F_{A} \times 1,44\right)+(28.342,925 \times 1,44 \times(0,72))-$

$(28.342,925 \times 4,20 \times(2,10))-(493.782,45 \times 4,20)=$

$\left(F_{A} \times 1,44\right)+(29.385,945)-(249.984,598)-(2.073 .886,29)$

$\left(F_{A} \times 1,44\right)=2.294 .484,943$

$F_{A}=\frac{2.294 .484,943 \mathrm{~N} / \mathrm{m}}{1,44 \mathrm{~m}}=1.593 .392,32 \mathrm{~N}$

$F_{A}=1.593,39 \mathrm{kN}$

Untuk mencari nilai Rc digunakan konsep keseimbangan momen titik $\mathrm{b}(\mathrm{Mв})$ berikut:

$\Sigma M_{b}=0$

$M_{A}+M_{D}-M_{C}+M_{E}=0$

$\left(F_{A} \times d_{a b}\right)+\left(F_{D} \times d_{d b}\right)-\left(R_{C} \times d_{c b}\right)+\left(F_{E} \times d_{a b}\right):$

$\left(F_{A} \times 5,64\right)+\left(F_{D} \times 4,92\right)-\left(R_{C} \times 4,20\right)+\left(F_{E} \times 2,1\right)=$

$(1.593 .392,322 \times 5,64)+(40.813,812 \times 4,92)-(R C \times 4,20$

$(119.040,285 \times 2,1)=0$

$(8.986 .732,696)+(200.803,955)-\left(R_{C} \times 4,20\right)+(249.984,598)$

$\left(R_{C} \times 4,20\right)=9.437 .521,249$

$R_{C}=\frac{9.437 .521,249 \mathrm{~N} / \mathrm{m}}{4,20 \mathrm{~m}}=2.247 .028,869 \mathrm{~N}$

$R_{C}=2.247,03 \mathrm{kN}$

Nilai safety factor maksimum material steel pada kondisi shock load adalah 16. Maka 


\begin{tabular}{|l|l|l|}
\hline FB & $386,4 \mathrm{kN}$ & $493,78 \mathrm{kN}$ \\
\hline RC & $1.826,43 \mathrm{kN}$ & $2.247,03 \mathrm{kN}$ \\
\hline
\end{tabular}

Setelah didapat nilai gaya pada setiap daerah pembebanan dan tumpuan, maka kita dapat menghitung tegangan tarik (tensile stress) berikut ini :

A. Front Hydraulic Cylinder Pivot

a. Kondisi Pembebanan Normal

$A=2 \times(p \times l), \quad A=2 \times(350 \times 180) \mathrm{mm}^{2}$

$A=126.000 \mathrm{~mm}^{2}$

Jadi,

$\sigma=\frac{F_{B}}{A}, \quad \sigma=\frac{386.395,8 \mathrm{~N}}{126.000 \mathrm{~mm}^{2}}$

$\sigma=3,067 \mathrm{~N} / \mathrm{mm}^{2}$

Nilai safety factor maksimum material steel pada kondisi shock load adalah 16. Maka besar tegangannya adalah :

$\sigma=3,067 \mathrm{~N} / \mathrm{mm}^{2} \times 16, \sigma=49,12 \mathrm{~N} / \mathrm{mm}^{2}$

b. Kondisi Pembebanan Overload

$$
\begin{aligned}
& \sigma=\frac{F_{B}}{A}, \quad \sigma=\frac{493.782,45 \mathrm{~N}}{126.000 \mathrm{~mm}^{2}} \\
& \sigma=3,919 \mathrm{~N} / \mathrm{mm}^{2}
\end{aligned}
$$$$
\sigma=\frac{F_{A}}{A}, \quad \sigma=\frac{1.280 .181,259 \mathrm{~N}}{84.000 \mathrm{~mm}^{2}}
$$

$\sigma=15,24 \mathrm{~N} / \mathrm{mm}^{2}$

Nilai safety factor maksimum material steel pada kondisi shock load adalah 16. Maka besar tegangannya adalah :

$\sigma=15,24 \mathrm{~N} / \mathrm{mm}^{2} \times 16, \sigma=243,84 \mathrm{~N} / \mathrm{mm}^{2}$

b. Kondisi Pembebanan Overload

$\sigma=\frac{F_{A}}{A}, \quad \sigma=\frac{1.593 .392,322 \mathrm{~N}}{84.000 \mathrm{~mm}^{2}}$ besar tegangannya adalah :

$\sigma=3,919 \mathrm{~N} / \mathrm{mm}^{2} \times 16, \sigma=62,7 \mathrm{~N} / \mathrm{mm}^{2}$

B. Bushing Slider Bracket

a. Kondisi Pembebanan Normal

$A=2 \times 2(p \times l), \quad A=2 \times 2(105 \times 200) \mathrm{mm}$

$A=84.000 \mathrm{~mm}^{2}$

Jadi,

$\sigma=\frac{R_{C}}{A}, \quad \sigma=\frac{1.826 .431,156 \mathrm{~N}}{84.000 \mathrm{~mm}^{2}}$

$\sigma=21,743 \mathrm{~N} / \mathrm{mm}^{2}$

Nilai safety factor maksimum material steel pada kondisi shock load adalah 16. Maka besar tegangannya adalah :

$\sigma=21,743 \mathrm{~N} / \mathrm{mm}^{2} \times 16, \sigma=347,89 \mathrm{~N} / \mathrm{mm}$

b. Kondisi Pembebanan Overload

$\sigma=\frac{R_{C}}{A}, \quad \sigma=\frac{2.247 .028,869 \mathrm{~N}}{84.000 \mathrm{~mm}^{2}}$

$\sigma=26,75 \mathrm{~N} / \mathrm{mm}^{2}$

Nilai safety factor maksimum material steel pada kondisi shock load adalah 16. Maka besar tegangannya adalah :

$\sigma=26,75 \mathrm{~N} / \mathrm{mm}^{2} \times 16, \sigma=428,0 \mathrm{~N} / \mathrm{mn}$

C. Hydraulic Cylinder Bracket Arm

a. Kondisi Pembebanan Normal

$$
A=2 \times 2(p \times l), \quad A=2 \times 2(105 \times 200) \mathrm{mm}^{2}
$$

$A=84.000 \mathrm{~mm}^{2}$

Persentase kenaikan nilai gaya dari kondisi pembebanan normal ke pembebanan overload sebagai berikut :

a. Front Hydraulic Cylinder Pivot

$\frac{493.782,45-386.395,8}{386.395,8} \times 100 \%=27,79 \%$ 


$$
\sigma=18,969 \mathrm{~N} / \mathrm{mm}^{2}
$$

Nilai safety factor maksimum material steel pada kondisi shock load adalah 16. Maka besar tegangannya adalah :

$$
\sigma=18,969 \mathrm{~N} / \mathrm{mm}^{2} \times 16, \sigma=303,5 \mathrm{~N} / \mathrm{mm}^{2}
$$

Nilai tegangan komponen arm excavator hitachi 2500 pada kondisi pembebanan normal dan kondisi pembebanan overload dapat dilihat pada gambar 3. berikut ini :

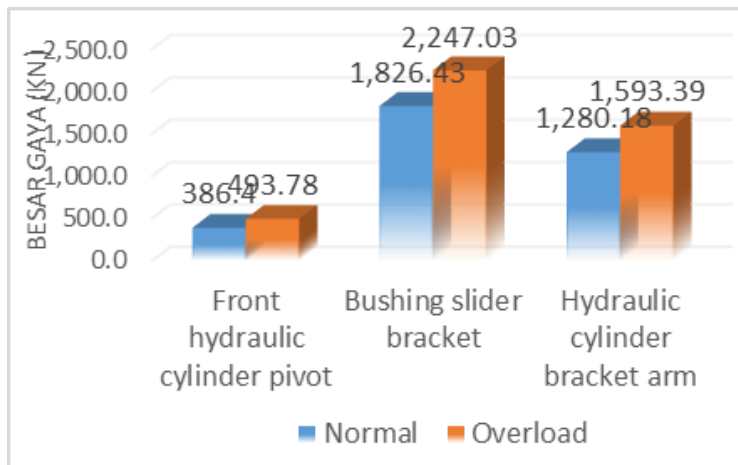

Gambar 3. Nilai Tegangan Pada Arm Excavator Hitachi 2500

Nilai tegangan pada bushing slider bracket pada kondisi pembebanan normal dan kondisi pembebanan overload dapat dilihat pada gambar 5. berikut ini :

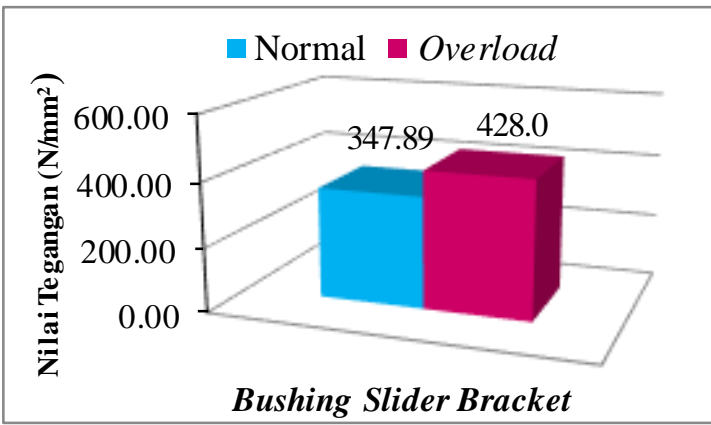

Gambar 5. Nilai tegangan Pada bushing slider bracket,

Persentase kenaikan nilai tegangan Pada bushing slider bracket saat pembebanan overload yaitu :

$$
\frac{428-347,888}{347,888} \times 100 \%=23,03 \%
$$

b. Bushing Slider Bracket

$$
\begin{aligned}
& \frac{2.247 .028,869-1.826 .431,156}{1.826 .431,156} \times 100 \%= \\
& \text { c. Hydraulic Cylinder Bracket Arm }
\end{aligned}
$$

$$
\frac{1.593 .392,322-1.280 .181,259}{1.280 .181,259}
$$

Nilai tegangan pada front hydraulic cylinder pivot pada kondisi pembebanan normal dan kondisi pembebanan overload dapat dilihat pada gambar 4. berikut ini :

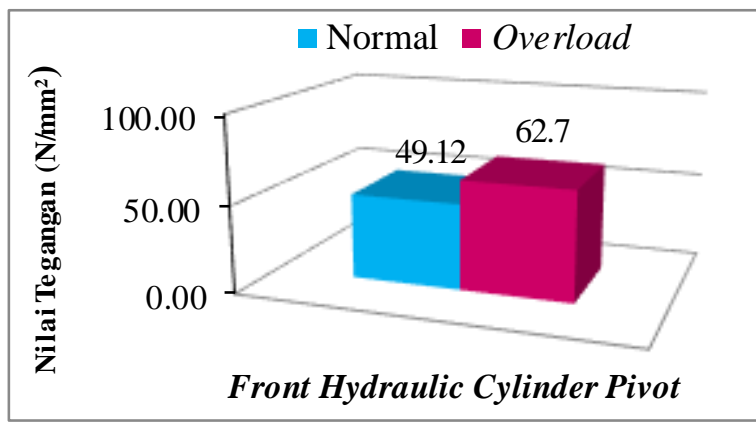

Gambar 4. Nilai tegangan pada front hydraulic cylinder pivot

Pada front hydraulic cylinder pivot, persentase kenaikan nilai tegangan dari kondisi pembebanan normal ke pembebanan overload sebagai berikut :

$\frac{62,704-49,12}{49,12} \times 100 \%=27,65 \%$

\section{Kesimpulan}

Hasil analisa data dan perhitungan kekuatan komponen arm excavator Hitachi EX2500 pada pembebanan overload diperoleh kesimpulan sebagai berikut :

a. Gaya pada front hydraulic cylinder pivot sebesar 493,78 $\mathrm{kN}$ dan nilai tegangan sebesar $62,7 \mathrm{~N} / \mathrm{mm}^{2}$.

b. Gaya pada bushing slider bracket sebesar 2.247,03 $\mathrm{kN}$ dan nilai tegangan sebesar $428 \mathrm{~N} / \mathrm{mm}^{2}$.

c. Gaya pada hydraulic cylinder bracket arm sebesar $1.593,39 \mathrm{kN}$ dan nilai tegangan sebesar $428 \mathrm{~N} / \mathrm{mm}^{2}$. 
Nilai tegangan pada hydraulic cylinder bracket arm pada kondisi pembebanan normal dan kondisi pembebanan overload dapat dilihat pada gambar 6 . berikut ini :

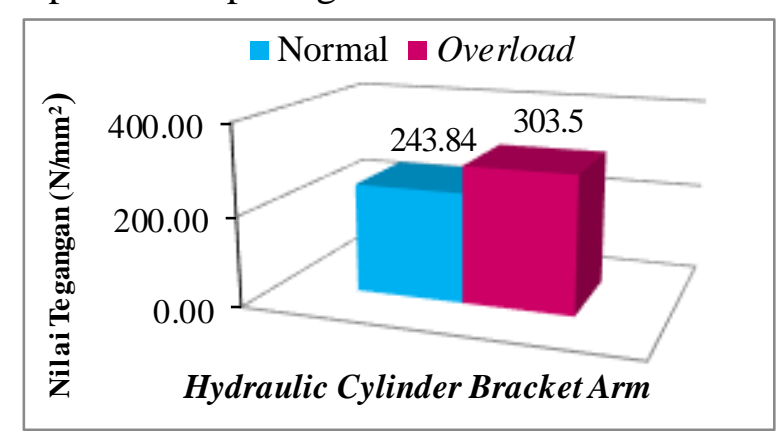

Gambar 6. Nilai tegangan pada hydraulic cylinder bracket arm

Persentase kenaikan nilai tegangan Pada hydraulic cylinder bracket arm saat pembebanan overload:

$\frac{303,504-243,84}{243,84} \times 100 \%=24,47 \%$

Material arm pada front hydraulic cylinder pivot terbuat dari material structural steel SS400 dengan batas tegangan ijin (yielding point) sebesar $205-245 \mathrm{~N} / \mathrm{mm}^{2}$, tegangan maksimum terjadi di front hydraulic cylinder pivot pada kondisi pembebanan overload sebesar 62,704 N/ $\mathrm{mm}^{2}$. Sedangkan pada bushing slider bracket dan hydraulic cylinder bracket arm, terbuat dari material high tensile steel HT590 dengan batas tegangan ijin (yielding point) sebesar 505-515 N/mm², tegangan maksimum terbesar terjadi di bushing slider bracket pada kondisi pembebanan overload sebesar $428 \mathrm{~N} / \mathrm{mm}^{2}$. Nilai kedua tegangan tersebut lebih kecil dari tegangan ijin material sehingga material-material pada komponen arm dinyatakan aman pada pembebanan standar maupun pembebanan overload saat proses pengangkatan.

\section{Daftar Pustaka}

1. Anonim. 2004 : Performance Handbook Ed.35, Caterpillar Inc. : Illinois.

2. Anonim. 2007 : $\boldsymbol{E X} \mathbf{2 5 0 0}$ Specifications: Brochure, HCM : Tokyo.

3. Anonim. 1994 : Repair Welding Manual, HCM : Tokyo.

4. Anonim. 2007 : Technical Manual : Manual Operational Principle EX 2500 Hydraulic Excavator, HCM : Tokyo.

5. Anonim. 2005. Pengenalan dan Aplikasi Alat-Alat Berat. Hexindo Adiperkasa : Jakarta.

6. Khurmi, R.S. 2005 : A Text Book of Machine Design. New Delhi.

7. Kurniawan, Taufik. 2009 : Studi Analisis Produktivitas Excavator Backhoe Hitachi EX 2500 dan Liebherr 994, Fakultas Teknik Pertambangan Institute Teknologi Bandung : Bandung.

8. Pongsapan, Lia. 2013 : Mekanika Teknik dan Statika Struktur, Fakultas Teknologi Industri Universitas Balikpapan : Balikpapan.

9. Peurifoy, R.L. 1970 : Construction Planning, Equipment and Methods Ed.2. Kogakusha Company Ltd. : Tokyo

10. Prasetya, Sambas, et al. 2008 : Proses Manufaktur dan Pemilihan Material Excavator Arm, Fakultas Teknik Universitas Indonesia. : Jakarta.

11. Suprihanto, Agus. 2008 : Mekanika Teknik Statika. Fakultas Teknik Universitas Diponegoro : Semarang 